\title{
Copies of Copies: Simulated Cities from Security to Logistics
}

\author{
ERSELA KRIPA \\ Texas Tech University
}

\section{Simulated cities are expanding and taking on new roles, merging military and civilian technologies in constellations of adapted and purpose-built urban forms. As security and commercial interests mingle in these geographies, our cities, homes, and bodies are implicated, foreshadowing a coming era of securologistics.}

\section{SIMULATED CITIES}

A new urban typology is emerging in the forgotten peripheries of empire, a faint echo of our urbanizing world. Simulated cities, purpose-built facsimiles of real-world urban environments, are emerging from a long, obscure, and often classified history of use in covert military training operations on secret sites, to find new uses and scales in mainstream applications for everyday commerce and private companies. As the scale and spread of these testing territories continues to grow, the simulated city is evolving new trajectories, resulting in shared facilities which hybridize the needs of both war and commerce. Freed and distant from the sites they once replicated, the simulated cities themselves demand the extent of land and complexity of infrastructure once reserved for the city proper, exhibiting autonomous characteristics of urbanization all their own.

Logisticians from the military and commercial sectors, both seeking the increased efficiency of urban operations, view these expansive brick-andmortar replicas with equal admiration. Both recognize the physicality of the constructed copy as a vital factor in delivering the necessary visual and material feedback for accurate testing of conceived urban actions, and the quantifiable, verifiable, and repeatable results that such physicality ensures. After decades of advances in the virtual systems which manage real-time logistics, both the military and civilian sectors are now seeking to hybridize virtual and computational models with input from material simulations, and the unpredictability that only real-world scenarios and physical sites can provide. While the technologies of security and commerce evolve exponentially in the digital realm, the physical world can be seen to augment and accelerate its findings. In the pursuit of total, immersive simulation, testing environments on both fronts are adapting hybridized approaches, achieving higher levels of realism, complexity, and scale.

\section{OBSTACLE OPTICS AND MORPHOMETRICS}

The similarities between military and commercial urban simulation strategies highlight important, shared attitudes towards urban environments across both security and logistic sectors. Shared spatial optics increasingly define the city in terms of morphological characteristics which would provide barriers to the advance of a localized operation. Whether the goal is a counter insurgent action or an automated delivery, the space of the city is conceived in both realms as a complex assemblage of obstacles, which provide a dynamic, ever-changing environment dependent on real-time sensing and networked feedback for the human or artificial agents to successfully navigate. Sensing mechanisms thus rewrite urban sensibility, problematizing both density and complexity, and seeking their avoidance.

Experiments in the simulated city will seek to gather and record the city's metrics, mapping the city's unpredictable morphologies, in order to design the actions of infiltrators - whether specialist assault teams or automated delivery devices. Driverless cars create point cloud data from advanced camera technologies, in order to locate barriers and adjust their routes. Infrared sensing penetrates buildings and ground to uncover hidden networks, opportunities for covert operations. The resulting morphometric database provides a new image for urban city as a problematized set of spatial discontinuities and ruptures, impeding the flows of the organizations which may seek its control. While data-gathering may at first be conditional on a particular operation or neighborhood, over time the amount of data on a particular city aggregates to form extensive, though necessarily incomplete, images of the city as impediments to overcome.

This paper will discuss shifting conceptions of urban space in two simulated cities, highlighting the emerging relationships between military and civilian urban simulation environments. In the town of Playas, organizers continue to adapt and expand an abandoned city to train military and security operatives for the future of urban warfare. At the Center for Innovation and Testing Evaluation (CITE), defense specialists are creating a vast logistics simulation city, intended for use by a range of civilian corporations in need of an intact and unpopulated urban fabric to test new technologies. Both cities are located in the New Mexico desert, where the vast uninhabited territory offers the perfect environment for undisturbed testing. Both sites can be read 


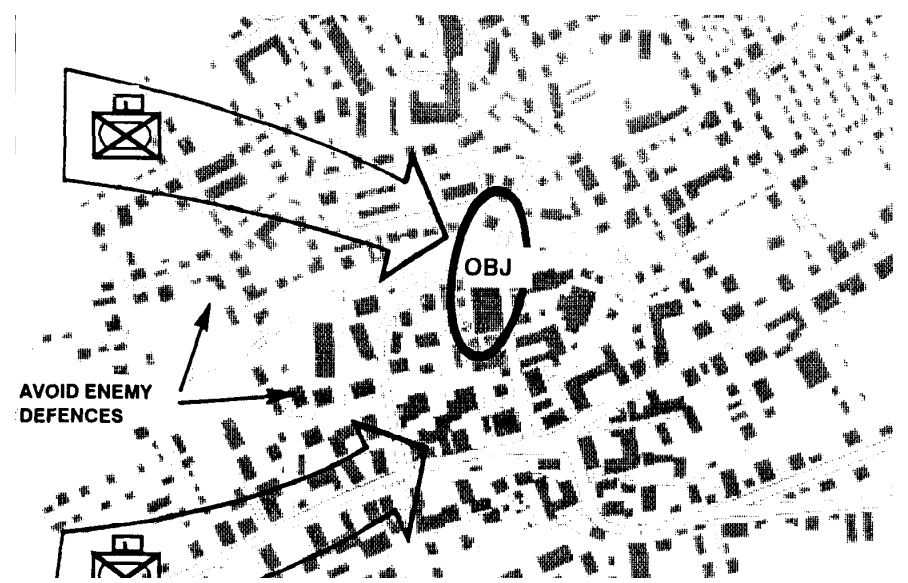

Figure 1: Seizure of a Key Objective, US Army FM 90-10-1 An Infantryman's Guide to Combat in Built-up Areas, 3-18 (public domain image)

as physical computers, calculating possible futures which merge technology, security, and commerce. As such they index, forecast, and indeed help to realize the city to come.

\section{THE MILITARY SIMULATED CITY}

The use of simulated cities has become the 'new normal' in US military training procedures. US-controlled territory, both domestically and abroad, is host to staggering numbers of purpose-built, simulated environments. Hundreds of sites around the world train American military personnel for the urban warfare and counterinsurgency operations they are likely to encounter once deployed ${ }^{1}$. The growing collection of military bases which sponsor such installations can be seen as an independent and autonomous transnational geography, transgressing national borders as a network of inter-related militarized zones. Zones of conflict thus expand beyond the intended theater of operations, encompassing also the cities and sites of the homeland. This geography is bound by shared rule-sets, operational logics, and representational techniques for engaging the city as a site of conflict.

The US Military has recently adopted new minimum standards for the physical environments of urban warfare training. Following closely the recommendations of the RAND corporation, a thinktank instrumental in developing military strategy, US military training has pivoted to view counterinsurgency in urban environments as a primary aspect of the threat environment for the foreseeable future. ${ }^{2}$ In this view of global urbanization, urban environments, especially those in the so-called global south, constitute a unique threat to US military and global security. Since $9 / 11$, significant resources have been devoted to building and upgrading training sites around the world to meet corresponding government mandates, ensuring that armed forces are familiar with the informal fabric of the developing megacity even before they are sent into battle. The use of simulated urban morphologies prior to battle reportedly significantly reduces both civilian and 'friendly-fire' casualties. Buoyed by such reported success, the simulation construction program has continued to expand. Among the many requirements shared between sites are a fixed set of urban typologies and infrastructures thought common to the future of conflict.

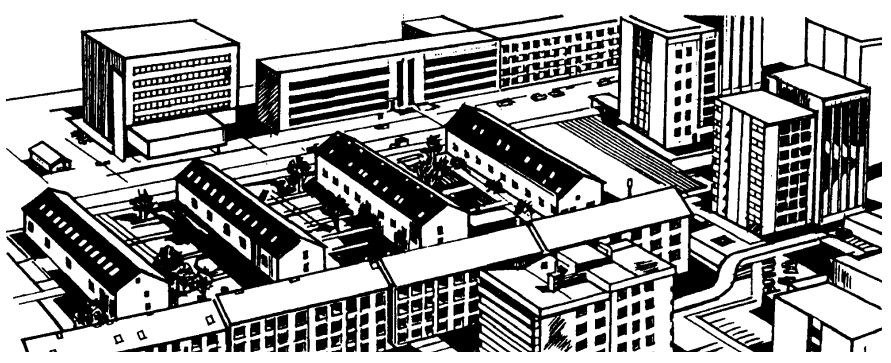

Figure 2: City Core, US Army FM 90-10-1 An Infantryman's Guide to Combat in Built-up Areas, 2-3 (public domain image)

Urban Operations (UO) training sites are required to include building typologies seen as antagonists in the hostile city, buildings which are easily or commonly appropriated by violent non-state actors (VSNAs), including paramilitary operatives and terrorist organizations, as spaces of defense, attack, or strategic importance. Thus, residential fabrics, buildings of religious worship (including churches and mosques), cemeteries, bridges, and other types of urban infrastructures are at the center of the war scenario, grafted into the simulation environment. As rapid global urbanization continues, advances in the informal city are absorbed into the training environment - as the inhabited cities grow increasingly more complex so too do the sites which mimic them.

These new planning standards for simulation index a changing attitude towards the space and dimensionality of war. Until the recent past urban warfare tactics were drawn in two-dimensional, planimetric view, with maneuver symbols drawn disproportionally to the intricate scale of the city. Large swooping arrows indicated similarly broad objectives. Symbols for 'overtake' would assume a flattening of the urban terrain on which they were drawn, (see Fig. 1) reinforcing an attitude that the city in war is a space to avoid. With the swell of urban insurgencies in the past decades, the representational methods of military strategists would also change.

Military strategists have, since failures of operations in Mogadishu and elsewhere, described the intense compression of the battlefield in contemporary urban warfare as the three-block war ${ }^{3}$. Protracted combat situations in the three-block war occupy an area the size of three city blocks, resulting in a complex overlay of military, civilian, and humanitarian actors. Combat in this scenario can be literally 'next-door' to peaceful residences, public buildings, peacekeeping missions and humanitarian supply chains.

In order to prepare for the three-block war, the military sees and draws the existing city in terms of zones of potential conflict, each with its own density and likely construction type. The spatial optics of the three-block war thus privilege maneuverability and the methods for achieving artillery dominance of the physical fabric of the city. The tools for mapping the city in this scenario are aerial and perspective drawings (see Figs. 2-4) which describe generic city neighborhoods, a kind of retrospective planning document which mines the existing city for an underlying code. Operations in such contexts are drawn and coded with a precise alphabet of maneuvers, equating building 


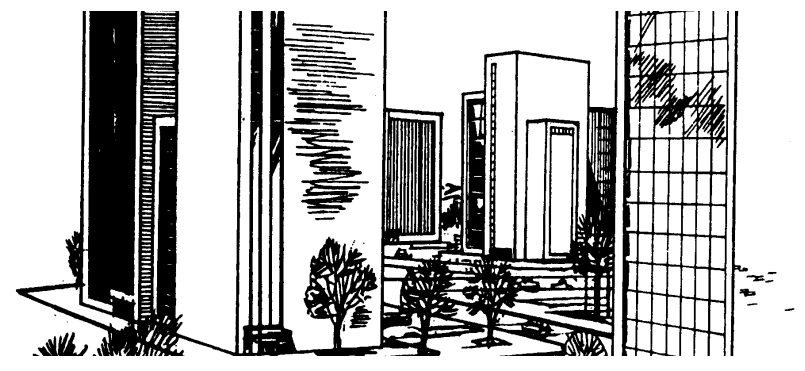

Figure 3: Outlying High-Rise Area, US Army FM 90-10-1 An Infantryman's Guide to Combat in Built-up Areas, 2-3 (public domain image)

type with ranges of military operatives, artillery, and strategy. These complex notational systems of urban military actions, drawn from the annals of recent urban military history, prefigures a new syntax for the planned simulated city.

In recent years, the urban battlespace has compressed further, demanding new methods of representation and a finer grain for strategic notation. The four-floor war is re-grafting the military's reading of the city as a three-dimensional space. Brigadier General Julian Alford of the US Marine Corps Warfighting Laboratory explains:

We are going to be on the top floor of a skyscraper, evacuating civilians and helping people,. The middle floor we might be detaining really bad people that we've caught. On the first floor we will be down there killing them. At the same time they will be getting away through the subway or subterrain... How do we train to fight that? Because it is coming, that fight right there is coming I do believe with all my heart. ${ }^{5}$

Sectional axonometric projections of cities, complete with building sections, above and below ground street and subway infrastructure, and airspace are now necessary devices in reorienting the optics of war (See Fig. 5). These multidimensional, cutaway devices, suggest that the interior, rooftop, and subterranean realms of the city act in tandem to replace the battlefield as a site of combat. This conception is echoed in the development of imaging technologies, weaponry advances, and training strategies which target this previously underexploited realm.

\section{PLAYAS}

Playas, New Mexico, is a former copper mining town that lost its population with the collapse of the mining industry. Nestled in the mountainous landscape of the New Mexico bootheel, the site sat underutilized and abandoned at the end of the 20th Century. Drawing on recommendations from the RAND report, ${ }^{6}$ government agencies appropriated the urban site as a 'ready-made' backdrop for urban warfare simulation.

Playas is now the background for simulated urban warfare, complete with functioning infrastructure, homes, streets and public spaces. New Mexico Tech (NMT) owns and manages the sprawling facility, through their Energetics and Material Research and Testing Center (EMRTC). NMT leases the facility to a range of potential 'customers', including a variety of security agencies, police forces, emergency responders, and the U.S. military.

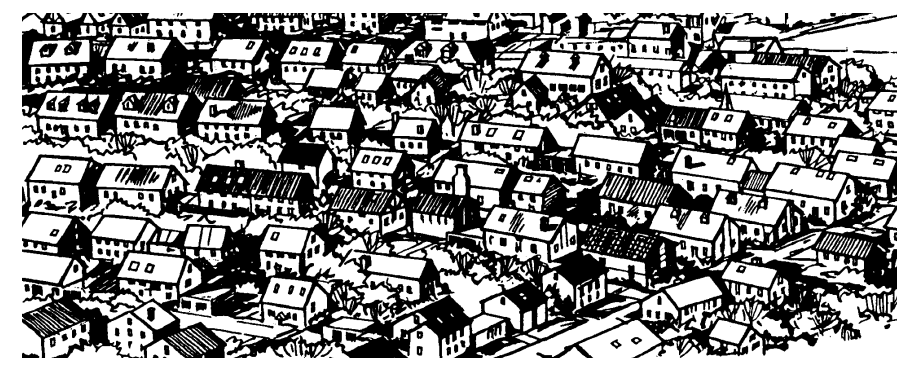

Figure 4: Residential Sprawl, US Army FM 90-10-1 An Infantryman's Guide to Combat in Built-up Areas, 2-3 (public domain image)

Organizers use not only the existing city, but the existing landscape and communications infrastructure to simulate conditions of deployment. A replica 'Afghan village' has been built in the mountainous terrain surrounding the original town, the mountains themselves appropriated as viable stand-ins for the Afghan geology. The village is accessible only by long drives on poorly maintained roads, which provide additional opportunity for convoy and vehicular training scenarios. Intentionally located beyond the reception of local mobile phone service, the isolation of the village simulates the physical and communicative isolation combat troops would likely experience in remote outposts. Once they have arrived, trainees may stay for weeks, making decisions and acting on their own without reliable connection to central command.

The need for hyper-real training has increased the difficulty and impact of such training, rendering it now more difficult than the reality it simulates. While strategists see value in "making the practice harder than the game," ${ }^{\prime 7}$ military personnel have been known to report PTSD symptoms after intense training sessions.

Afghan refugees and other actors are hired as role players, living in the village for two or three months at a time. Scenario planners relegate control of the city to these 'insurgent' role-players, using them as agents of chaos who enact the 'feral ${ }^{8}$ ', the informal, and uncontrollable conditions of densely populated environments. Role players are hired to spend their days simulating their lives back home for the benefit of the simulation's authenticity. For the role players, simulation is enmeshed in the reality of daily life, deeply disturbing the distance between the real and the unreal. Cameras are constantly surveilling the mock environment, registering the position of role players, capturing every move. While the ubiquitous surveillance infrastructure is designed to capture the role players' performances in scripted scenarios, it might equally capture the domestic 'off-script' daily habits of the actors as well. A similar confusion of the familiar with the unfamiliar is palpable in the African market area, which occupies one of the main streets in the original town. With the products and furnishings of a traditional market, and simulated meats and vegetables on display, from certain vantage points the place looks as if it is actually inhabited.

The staged cities and villages are even more indiscernible from actual settlements to those who are unaware of the site's peculiar use. Since Playas is one of the more substantial built environments for 


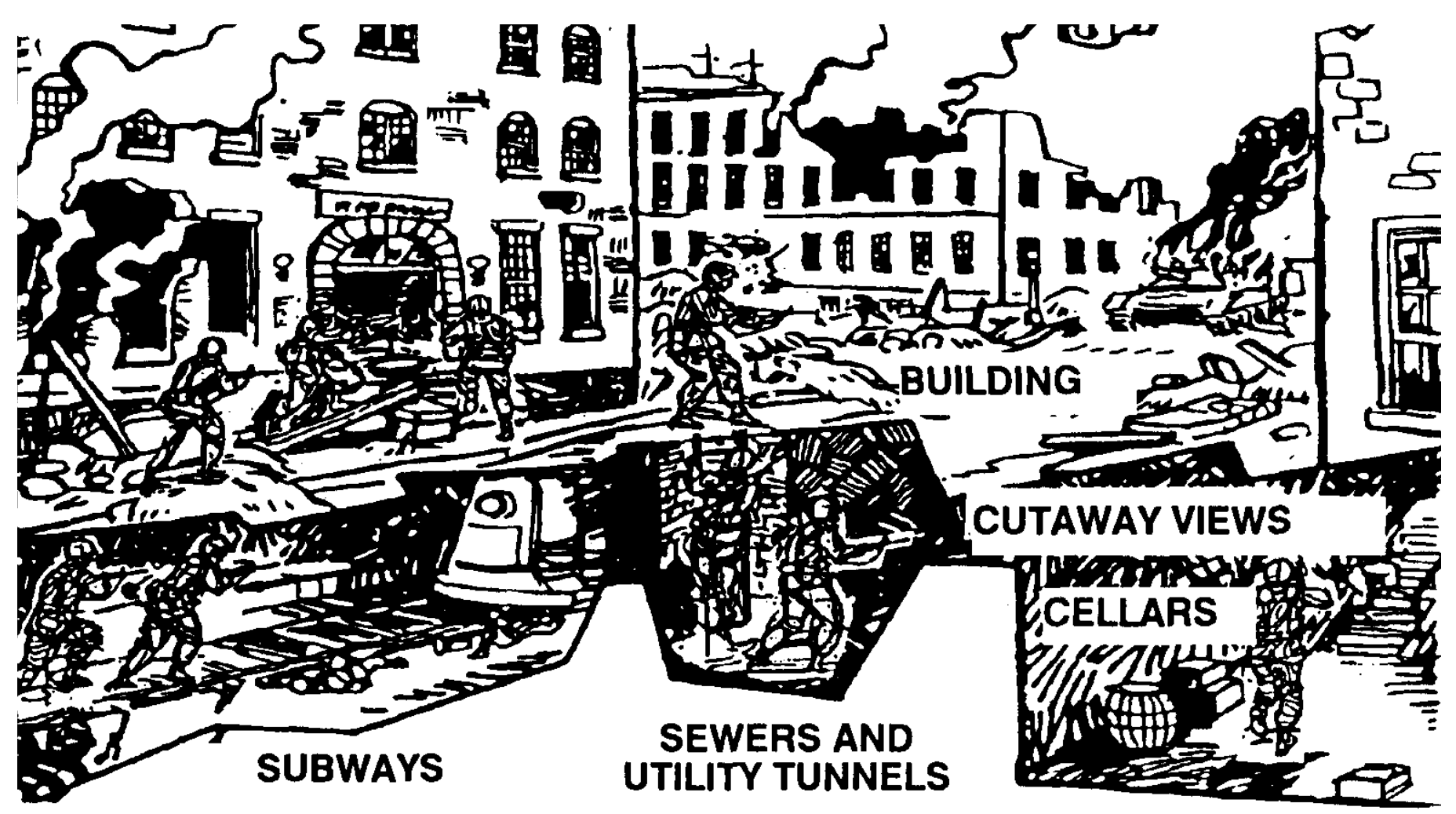

Figure 5: Underground Systems, Charateristics of Built-up Areas, US Army FM 90-10-1 An Infantryman's Guide to Combat in Built-up Areas, 1-4 (public domain image)

miles around, it has become an obvious beacon for undocumented migrants seeking shelter and water. Following the light of the homes and test facilities, or the infrastructural easements on their journey through the harsh desert, migrants sometimes happen upon the test facilities by chance. Resting for a night in a simulated home, these temporary occupants unknowingly run the risk of being swept up in a training scenario, or being discovered as scenario planners secure the home to begin the day's training.

\section{THE LOGISTIC SIMULATED CITY}

The appetite for simulation has spread from the military to the civilian sphere. As 'real-world' urban environments evolve, new types of simulated cities are being created and tested to help shape the space of global commerce. Logistics companies, working in tandem with defense contractors, adapt military simulated city precedents, with only minor modifications, to test emerging civilian infrastructures and technologies. Driverless car manufacturers, commercial drone delivery enterprises, humanitarian aid organizations, and other civilian companies whose products require full-scale, physical proof-of-concept, inhabit a growing landscape of civilian simulation.

In such a logistic city, war comes home. ${ }^{9}$ Military expertise in the administration of death, developed in the outposts of empire, ${ }^{10}$ finds new outlets on the domestic front, through urban proxies managing landscapes of loss. This logistic city secures territory under the guise of managerial logic, ${ }^{11}$ reorganizing complex networks of materials,

services, and resources to ensure strategic advantage. By inflecting urban processes, the logistic city affects urban populations, using infrastructure as its arsenal and site of action.

The city that cannot be measured or predicted becomes an unknown variable in the efficiency formula of logistical organization. The logistic city inadvertently criminalizes the unsanitary, the unclean, the inefficient, and the excessive, casting away unpredictable informality.

CENTER FOR INNOVATION, TESTING + EXPERIMENTATION (CITE)

CITE, the largest civilian simulated logistic city to date will soon be constructed in the New Mexico desert. This logistic city offers to help companies efficiently navigate what organizers describe as legacy infrastructure. ${ }^{12}$ This logistic city shares many of the same spaces indeed 'targets' - which the military simulated city engages, offering a counterpoint to military intervention as the only possible agent of incremental change. Recognizing that our cities' physical fabrics and organizational systems are a substrate upon which new layers of human and technological intervention will soon take root, the project instead takes a positivist, near techno-futurist view of increased urbanization. The CITE developers promise that their facility will allow new technologies to integrate into the nation's urban, suburban legacy infrastructure and to provide detailed measurable results on their impact on the economy. ${ }^{13}$

Developed by Pegasus Global Holdings, the project draws on the military experience of its initiators to extend the tactics of military urban simulation into the domestic realm. As an authorized vendor and manufacturer of defense technologies for the US military, ${ }^{14}$ Pegasus brings years of experience, born and tested in conflict, to bear on the peacetime development. The firm's expertise in crafting 
the technologies of war is evident in the project's overall technophilic drive towards a complete logistical and infrastructural efficiency, and is made manifest in the technological systems it deploys on site. The range of advanced imaging, sensing, and spatial devices the company will bring to the New Mexican desert include underground smart infrastructure, drone delivery control centers, feedback sensing in driverless cars, as well as specific districts that specialize in unique types of infrastructure. ${ }^{15}$ The latest technologies are transferred fluidly on these sites between military and civilian space: drones, remote surveillance, and facial recognition softwares coevolve on site.

If it were an occupied city, CITE would house about 35,000 inhabitants, however in the interest of efficient testing the city is not designed for human inhabitation. Without the role players evident in Playas and other military training facilities - or the social and linguistic complexities which they may bring to an urban experiment - here organizers are focused on the repercussions of the physical city itself. Excluding the employees who will manage its infrastructural softwares, no one will call CITE home ${ }^{16}$.

Much like the military built its cities with a specific warfare scenario in mind, the designers of CITE planned the city in terms of its vulnerable critical infrastructure ${ }^{17}$ and other targeted components. CITE is divided in easily discernible districts (the water district, the energy district, the development district, ${ }^{18}$ etc.), all compete with functioning underground infrastructure. However, as dense urban environments are not easily separated into districts of siloed infrastructures, a lack of resolution between the reality of the city and the simulated city emerges, begging the question: If not the real city, what is tested here?

Representationally, the logistic city is conceived and executed in the language of commercial architectural production, with renderings and organizational drawings amassing for promotion of the project by architects Perkins + Will. ${ }^{19}$ As the military city is planned in secrecy, the logistics city is planned in public, and for a public - a series of customers for whom it must be easily understood, its parts commodified, and sold.

While the military simulates the unpredictable, the chaotic, and the informal, this new logistics city is designed to compute the opposite, optimizing civilian interventions and achieving high-efficiency solutions, perfecting the interface of new technologies, forms of commerce, and human behavior within a generic urban order.

\section{SECUROLOGISTICS - HYBRID FUTURES}

Nowhere is the tendency for security space to become grafted into the space of the city more legible than in these spaces which simulate their future. By analyzing these sites we can understand emerging potentials and threats such hybridization poses to our cities, our public spaces, and our lives.

Both military and civilian uses of simulation suspend the idea of control of the city from traditional notions of 'policy', 'planning', and 'design'. The logisticians of such securologistic space assume a technoscientific autonomy for the processes which will manage their simulated cities in the absence of authority, centrality, or a 'control center'. Shared outlooks between security and logistic interests are manifest in the typologies most commonly deployed by the simulated citymakers - both types share municipal buildings, without any municipal leaders. The simulated city, in order to be effective, is thus 'de-planned'.

These two simulated typologies share parallel trajectories while sharing historical materiel. As foreign interventions require fewer bodies and physical space to maintain a presence abroad, the material world of the military has indeed come home. In the spaces of domestic securologistics, an expert military brings with it the retired equipment and logistical intelligence acquired in foreign battlefields, reconscripted in service of new economic needs. Pegasus is dedicated to "commercializing military weaponry for the global market," while shaping the spaces of urban commerce.

As testing at CITE and similar installations progresses, results will be measured increasingly in economic indices. The untestable and unretrofittable, unplanned city will increasingly prove burdensome to goals of logistics, which are designed to minimize inefficiency and maximize profit. As the urban environment itself is the greatest imposition to the free flow of capital and goods, the securologistic search for smooth space will put increasing pressure on the complex fabrics and multiple, competing demands which have shaped urban space thus far. As security interests demand smooth occupation and logistics interests demand smooth interfaces, they are recasting the city as a new set of problems to be solved.

While the majority of the world's population continues to flock to urbanized environments, ${ }^{20}$ the city becomes increasingly unplanned and informal, characteristics inherently antagonistic to the securologistic city. The legacy infrastructure of current cities escapes smart logistics, creating conflict between the unplanned and the planned. Securologistics, and its growing morphometric database is cast as the arbitrator of disputes within the public and private realm. Data collection leads to forecast, forecast to intervention. Inefficient or unregulated urban patterns are associated with inefficiency, later fined, then criminalized. That 'off-the books' addition, DIY storm cellar, or extra floor could be flagged in direct violation of the securologistic spread, landing its informal constructor on a watchlist. 
ENDNOTES

1. See Kripa, Ersela and Stephen Mueller. Fronts : Security and the Developing World. ORO Editions. Forthcoming.

2. See RAND. "Preparing for the Future Inevitable." http://www.rand.org/content/ dam/rand/pubs/monographs/2006/RAND_MG439.pdf

3. Krulak, Charles C. "The Strategic Corporal: Leadership in the Three Block War." Marines Magazine Jan 1999. http://www.au.af.mil/au/awc/awcgate/usmc/strategic_corporal.htm

4. Manaugh, Geoff. "The Four-Floor War." BLDGBLOG. Dec 2015. http://www. bldgblog.com/2015/12/four-floor-war/

5. Judson, Jen. "US Troops Need Training To Battle in Future Megacities, Marine General Warns" Defense News. 4 Jan 2016. http://www.defensenews.com/story/ defense/training-simulation/2015/12/28/us-troops-need-training-battle-futuremegacities-marine-general-warns/77826210/

6. RAND

7. See Nagl, John A. Knife Fights: A Memoir of Modern War in Theory and Practice. Penguin Press, 2014.

8. See Norton, Richard. "Feral Cities." 2003 and "Feral Federation", project by AGENCY documented at www.feralfederation.org

9. See Stephen Graham, Cities Under Siege - The New Military Urbanism, London, Verso, 2011, 21

10. See Gillem, Mark. America Town - Building the Outposts of Empire.

11. See John May. "The Logic of the Managerial Surface." In Praxis 13 : Ecologics.

12. http://www.pegasusglobalholdings.com/test-center.html

13. Kasowatz, Jon. "An Urban Platform for Big Thinkers, Big Systems. ASME. Sep 2015. https://www.asme.org/engineering-topics/articles/technology-and-society/ urban-platform-big-thinkers-big-systems

14. http://www.pegasusglobalholdings.com/about/about-pegasus-overview.html

15. Beauchamp, Scott. "A Giant, Fake City in the Middle of the Desert."

The Atlantic. 19 May 2015. http://www.theatlantic.com/technology/ archive/2015/05/a-giant-fake-city-in-the-middle-of-the-desert/391652/

16. Monks, Kieran. "CITE: The \$1 Billon City That Nobody Calls Home." CNN. 6 Oct 2015. http://edition.cnn.com/2015/10/06/business/test-city/

17. See Coward, Martin. "Network-Centric Violence, Critical Infrastructure and the Urbanization of Security." http://sdi.sagepub.com/content/40/4-5/399.abstract

18. Beauchamp

19. http://perkinswill.com/work/cite

20. United Nations. "World Urbanization Prospects 2014." https://esa.un.org/unpd/ wup/Publications/Files/WUP2014-Highlights.pdf 